\title{
The use of music in group educational activities in Family Health
}

\author{
Líliam Barbosa Silva ${ }^{1}$ \\ Sônia Maria Soares² \\ Maria Júlia Paes da Silva ${ }^{3}$ \\ Graziela da Costa Santos ${ }^{4}$ \\ Maria Teresinha de Oliveira Fernandes ${ }^{5}$
}

Objective: describe how music is used in the development of group educational activity in Family Health. Methods: a qualitative, descriptive and exploratory study, developed with 10 group coordinators, distributed in five basic care units in Belo Horizonte, Minas Gerais, Brazil. Data were collected from March to July, 2009, with non participant observation in the group itself, and semi-structured interviews with the coordinators. Information was organized and categorized according to thematic analysis. To interpret the data, the Snyderian concepts in addition to theoretical references about music, communication and health education were used. Results: three thematic nuclei were found: the affective dimension of music; recreative dimension of music and the reflexive dimension of music. Conclusion: an attempt by the coordinators was observed, to overcome the pathological barriers with the use of music, considering the group as a whole. As advancement for the production of knowledge, this study shows the need for qualification of these coordinators, by means of workshops and constant follow-up of their musical practices.

Descriptors: Group Structure; Music; Communication; Family Health Program; Nursing.

\footnotetext{
${ }^{1}$ MSc, RN, Escola de Enfermagem, Universidade Federal de Minas Gerais, Belo Horizonte, MG, Brazil.

2 PhD, Associate Professor, Escola de Enfermagem, Universidade Federal de Minas Gerais, Belo Horizonte, MG, Brazil.

${ }^{3}$ PhD, Full Professor, Escola de Enfermagem, Universidade de São Paulo, São Paulo, SP, Brasil.

${ }^{4}$ Master's Student, Escola de Enfermagem, Universidade Federal de Minas Gerais, Belo Horizonte, MG, Brazil.

${ }^{5}$ Doctoral Student, Escola de Enfermagem, Universidade Federal de Minas Gerais, Belo Horizonte, MG, Brazil.
} 


\section{Introduction}

Since the primordial times of humanity, music has been part of man's life and has acquired different functions, such as artistic, educational, therapeutic and religious forms. Plato and Pythagoras referred to music as an instrument capable of harmonizing the human being. In the 19th Century, Florence Nightingale mentioned it as a tool for care ${ }^{(1)}$.

In the context of Brazilian nursing, music has been used as a complementary resource in the care of the human being, at all ages, with the goal of restoring balance and possible well being, in addition to favoring communication and frequently, to broaden the individual consciousness in the health-disease process ${ }^{(2)}$.

Researches conducted by nurses have revealed the therapeutic potential of music in reducing pain, stress and anxiety, promoting muscular relaxation, recovering memories, promoting comfort, or by helping people reconstruct their identities, integrate them and provide the construction of positive self-esteem ${ }^{(3-4)}$.

Particularly in the field of Family Health, it was verified that music is used in health education activities, which could facilitate people's participation in educational groups. Learning made feasible by music offers interdisciplinary possibilities, contributing to the construction of personal and social values, improving cognition and the capacity to solve day-to-day problems, making this more pleasurable and efficient ${ }^{(5)}$.

From this perspective, the group coordinator appears to interact with the members with the intention of constructing new knowledge and deconstructing deep-seated erroneous knowledge, without overlooking the knowledge and culture each individual brings within himself/herself as the basis of knowledge. This health educational modality refers to the precepts of Progressionist Pedagogy, which begins with the students' needs and aspirations in their day-to-day life, to encourage ruptures, leave the immediate, and reach the theoretical(6). Teaching leads students to starting with that which they like as the objective of knowing and understanding the production of great masters, with these being guides in the quest for knowledge( ${ }^{(7)}$.

In view of the foregoing, the group coordinator needs to be prepared to act in new health education models, assuming new tasks and suiting himself/herself to changes arising from the present health policy in force in the country, whose aim is the integrality of care. It is expected that the coordinator is a communicator capable of arousing the participants' interest by means of strategies that could guarantee that they are kept in the group, considering the cognitive and psychological factors involved in the learning process, which may be achieved through music.

Therefore, the presupposition of this study was that music is an advantageous strategy for educational actions, communication vehicle and group integration. Thus, it was sought to contribute towards answering the following question: how have the coordinators communicated with education groups in Family Health, considering music as a teaching-learning strategy?

The justification for conducting this study is the consideration that up to now, there are few researches in this area that present non traditional strategies in favor of more participative health education. In spite of the prevalence of groups focused on disease, in practice, there is predominance of communicational practices of information being passed on by the coordinator, centered on the behaviorist and prescriptive discourse ${ }^{(8)}$, one observes a trend towards the use of pedagogical strategies that point towards creative and participative pathways that deserve to be explored.

In view of the foregoing, the aim of this study was to describe how music is used in the development of group educational activity in Family Health.

\section{Methods}

This qualitative, descriptive and exploratory study, was developed with 10 group coordinators, distributed in five basic care units in Belo Horizonte, Minas Gerais, Brazil.

The informants' inclusion criteria were: belong to complete Family Health teams (composed of a doctor, nurse and two medium level nursing professionals); coordinate groups that performed activities of an educational nature; have used music during group activity, and agree to participate in the study.

Data were collected from March to July, 2009, first with non participant observation in the group itself during the activity, and after this, by semi-structured interviews with the coordinators. The guiding question was "Tell me how music is used during the group activity, considering it as a strategy in the teachinglearning process". Unexpected questions were added as the informant's answers were received, to explain some of the situations revealed.

The main topics of the non participant observation included: content discussed at each meeting when music was used as a strategy in the teaching-learning process; 
forms of the coordinator's communicative intervention in the group (congruous with the preventivist-oppressive, pedagogical board model, prescriptive of conduct/ behavior and blameful, infantilizing, reducer of collective problems; or in agreement with the New Promotion Model - facilitator of free expression and autonomy, empathetic communicator, constructionist, welcoming, uses active listening, in addition to promoting the ability to overcome alienation $)^{(9)}$ and relationships established between the participants, considering symbols, signs and discourses that demarcate places and competences of speech $^{(10)}$.

Thirteen meetings were followed-up, the observations of which generated note taking of theoretical, methodological and content aspects, producing a field diary with a continuous and cursive description of the verbal and non verbal manifestations. This information was recorded in manual writing, audio recording and transcription of data.

Only the coordinator was interviewed, as he was the mediator of the group ${ }^{(11)}$, who organized the contents to be discussed, and at the same time interfered in conducting the meeting, , questioning, determining and interpreting the group phenomena. This appears to contribute to the greater or lesser involvement of the participants in the proposed objectives.

Interviews were held with 10 persons: a doctor, five nurses, a mid-level nursing professional, two community health agents ( $\mathrm{CHA}$ ) and a social assistant. It is pointed out that it was not possible to interview one nurse as she was on maternity leave. These interviews occurred individually, were saved in MP3 format and transcribed in full.

The criterion of theoretical saturation was adopted for the conclusion of data collection; that is to say, it was interrupted when no new or relevant datum was found(12).

The information obtained was organized and categorized according to thematic analysis(13). After transcription of the interviews and field observations, the material was fully and exhaustively read for preanalysis and exploration of the data. After this, charts were systematically organized, in which the units of meaning were recorded, with later classification into nuclei of meaning and thematic area.

To interpret the data, not only the theoretical references about music, communication and health education were used, but also the Snyderian concepts (14), whose thinking made it possible to reflect on the need to provide the member of the group with motivation to learn, whose knowledge arises from the subject-object-reality.
The study was approved by the Research Ethics Committee of the Federal University of Minas Gerais (Protocol ETIC 133/08) and by the Ethics Committee of the Municipal Secretary of Health of Belo Horizonte (Protocol 044/2008). All the subject of the study signed the Term of Free and Informed Consent, including the participants in the groups observed. To guarantee anonymity, the informants were identified by fictitious names.

\section{Results}

The studied groups were constituted predominantly by women $(80.2 \%)$, in the age-range from 60 years or over $(70.0 \%)$. A mean of 21 participants per group was observed, whose meeting occurred with a weekly $(85.7 \%)$ or fortnightly $(14.3 \%)$ frequency.

The coordinators' age ranged between 25 and 53 years. Of the total 7 were women and 3 were men. Only 2 of the informants had been trained to work with groups.

When asked about their experience with music in the group, these descriptions could be summarized in three categories: "The affective dimension of music". "The recreative dimension of music" and "The reflexive dimension of music".

\section{Category I: The affective dimension of music}

This category encompassed the construction of the meanings of music mingled with emotions, feelings, desires, interests and motivations of the group, which is in a constant relationship with the sociocultural context.

For some of the interviewees, music contributes to greater empathy between the coordinator and the other members of the group.

[...] our approach is through music, we get together to sing. With this activity we become a more empathetic identity (Rodrigo - ACS).

Another statement shows recognition of the need for the coordinator to be prepared to observe how each member of the group perceives and experiences a certain piece of music in a specific moment of the group process, seeing that this artistic expression may cause sensations and reactions, so that the participators feel emotion. In the opinion of one of the interviewees, the fact of listening to the participant of itself alone is therapeutic.

[...] one needs to have an ethical commitment to not only be doing something, but also to be accompanying. Quite often they were monologues, one listened more than one said anything. The person only remembered the music and cried a 
little, told one about something personal. Sometimes that was all the person needed (Beatriz - nurse).

However, in practice, one observed that the coordinator did not always have the ability to capture and deal with the existent feelings that normally emerged in the group events during the activities that used music.

The Group arranged in a circle. CHA Teresa steps out of the circle and asks the participants to close their eyes and listen to the music [...], starts talking about donating feelings and joy. After a few minutes asks everyone to open their eyes slowly. One of the members feels moved, seeing there are tears in her eyes. She wipes away the tears with her hands. It was a lady whose husband died two weeks ago. The CHA is behind this participant and does not perceive what has happened. Blood pressure checking begins (NO - UBS 1).

Moreover, it was observed that by means of music there was the possibility of bringing out nuances of past life, evoking memories that are part of the narrative of life of each member of the group.

[...] there are some that say the following: When you sang that song, I was reminded of something so sad in my life and I got home and cried. Then I said: So the group was good [...]. No! I cried because I remembered so many good things that I have been through and that I no longer remembered. [...] childhood problems [traumas] are also always remembered because we sing "Atirei o pau no gato" (a typical Brazilian nursery song) (Beatriz - nurse).

\section{Category II: The recreative dimension of music}

In this category there was an approach to moments of entertainment, of joy and relaxation in the group, provided by the music that allowed the barriers imposed by the group discussions focused on the pathology to be overcome. In addition, this artistic expression has potentiated the group in the search for quality of life and has contributed towards increasing the participation of the community in the groups.

[the group] was tiresome because we spoke mostly about disease $[. .$.$] , but at the time [...] the nurse wanted to take the$ group out of the unit and work with another way of looking at things, taking a look in the sense of quality of life, not holding oneself to that thing of being a diabetic [...]. And that is how we started working with music. [...] we even had a lively little party to celebrate. [...] in this one year the group reduced the demand for welcome, (blood) pressures are more controlled (Gabriela mid-level nursing professional).

Another finding of this study concerned the cheerful and relaxed atmosphere provided by the music, which could drive people to seek educational groups, enriching interpersonal relationships, and thus diminish loneliness.
The group, therefore, becomes a space for sociability.

[...] they liked the group very much. They enjoyed themselves. I perceive the lack (of affection) in them. They go for pleasure [...] many of them live alone, others have married children, so they live a lonely life. So it is a time when they can go out, of leisure, of talking (to others) (Gabriela - mid-level nursing professional).

The coordinators used music to perform relaxation by verbal induction with the intention for focusing the participants' attention on themselves, enabling them to become aware of their bodies and preparing them for the end of group activity:

[...] there is something very good about music, which is relaxation. You join relaxation with the content music brings. If they are lyrics that lead you to conducting a pleasant theme, it helps you. But it was much more than was expected [...]. Here I perceived that they needed something more. These pills and anti-depressives alone weren't going to work (Beatriz - nurse).

To the sound of music - sounds of nature - and with a low soft voice, nurse Amanda asks everyone to breathe deeply, find a comfortable position [...]. Let's transport the body to a delightful place. It could be to the countryside where you were born [...]. They listen to the music. The sound of water washing over their shoulders, taking away all the tension [...]. The group demonstrates concentration (NO - UBS 1).

Music was also used as a strategy the announce the arrival of a latecomer member of the group, or to encourage the participation of persons who were quieter, not very participative, or even to the contrary, a strategy to interrupt the excessive chatter of some participant, exemplified as follows:

Twenty-six minutes after starting the group, a member arrives: Good afternoon. I am late. Laughter. CHA Virgínia, on seeing her, starts singing: I was just talking about you (three times). Welcome to our meeting. Another member accompanies with the tambourine. The other members also start singing (NO - UBS 2).

Sometimes, he [participant] doesn't have the courage to talk and there are people who are extremely shy, then I choose more provocative music, because I stopped and reflected this (Beatriz - nurse).

When the person is talking a lot, we start the rehearsal. The music takes this away a little, as if the music were a way of saying this: So that's good, Mr. So-and-so, let's sing this now. And then we start singing the song. [...] the rehearsal is a way of giving a signal that you have already had a lot to say (Rodrigo - ACS).

Another strategy used by the coordinator associated with music is with respect to the senior dance. In this study, this modality of dancing was explored in one of the meetings coordinated by the social assistant Cristiane, 
who counted on the help of a nurse, who at the time was a reference at the Municipal Secretary of Health in Belo Horizonte to divulge this practice. During the activity, one observed moments of great contentment on the cheerful faces of the group, full of vitality, documenting this moment. The members enthusiastically repeated the low impact choreography, short light steps with smooth movements, respecting the limits of each participant.

I always seek dynamic activity, because the elderly person cannot cope with only listening the whole time. [...] I think that through playfulness, such as senior dancing, one works very well, and it does not become something tiring. [...] Creativity and flexibility has to be put into practice the whole time (Cristiane - social assistant).

Another important aspect observed in the groups was the disposition of some of the coordinators to provide the elderly with activities that would involve singing or playing musical instruments, described as follows:

[...] we still have [...] two gentlemen who play (an instrument). It's a free day [...] (Amanda - nurse).

A differentiated objective to propose singing was observed in one of the groups under study, whose members met weekly to rehearse old Brazilian songs, with the intention of conducting a monthly serenade at the home of the bedridden in the community, denominated Serenade of the Bedridden. In the opinion of one of the coordinators, this is also a way of socialization of the person who, at that time, is frail and restricted to staying at home:

[...] in the group of friendly companionship our approach is [by means of] music. We rehearse the songs to perform a [...] serenade for the bedridden, [...] a work of socialization with them (Rodrigo - ACS).

\section{Category III: The reflexive dimension of music}

This category led to exploration and problematization of the situations experienced by the group mediated by music, which stimulates critical-reflexive thinking among the members in the search for greater perception of oneself and one's relationship with one's context.

In this study, music appears to promote selfknowledge, reflection and perception of the other, when there is socialization in speech in seeking problematization of day-to-day situations, important aspects for personal development as well as group and social integration.

Communication takes place in an interactive manner with the participation of the group, not in a way of passing on information, but seeking by seeking their knowledge to enable one to seek knowledge in common [...]trying to close in more on problematization. [...] music helps one to work in this way (Amanda - nurse).

Another aspect that permeated the possibility of using music in group work concerned its conscious use in order to maintain an ethical attitude related to respect for the autonomy of the member in desiring it at certain times. In this study, there was evident need for the coordinator to identify and respect the preference of the other person for a certain style of music, in order to sustain its positive influences, otherwise, it could work as yet another stressful factor, or trigger pre-task moments in the group, shown as follows:

We only communicate through music, which are the most popular pieces of Brazilian music, because it is a group formed mainly of elderly persons (Rodrigo - ACS).

If the group said anything, I made a note of it, and the next time that I would bring a piece of music, I would try to play the song he had said he preferred. In truth it takes much attention to really feel people (Beatriz - nurse).

The group discusses the songs they will play during the ball they are organizing. CHA Rodrigo comments: What I think is that we may dose (the different types of music): rock' $n$ roll, Elvis Presley, Roberto Carlos [...], to please all age groups. A participant comments: Yes. Now if they play funk, and signal with their hands indicating it's time to get out, I say bye-bye and oh, I get out (NO - UBS 2).

One of the coordinators emphasized that one does not always achieve one's objectives, with a good reflection in the group, due to the very story of people's lives.

[...] the people with whom we work have a past history of a great deal of suffering, usurpation of rights, including those related to aspects such as nutrition, physical, biological, poorly cared for chronic diseases, poorly cared for diseases of childhood in addition to lack of opportunity to study, read, politics, therefore, this limits their involvement and participation in the group (Carlos - doctor).

\section{Discussion}

In this study it was observed how difficult it is for the coordinator to ensure the accurate perception of the messages that emerge from the group, particularly those that denote the emotive effect among the members. Some of the participants did not passively assimilate the message vehicled in the coordinator's speech, which could have been potentiated by ambiental music. They did react to the meaning in relation to their worries, system of reference, mostly because every human being has the communicative competence to see the world in his/her own way, which must be recognized and respected by the coordinator ${ }^{(15)}$. In these cases, it 
would be interesting for the coordinator to perceive, and afterwards verbalize the occurrence with the member, in such a way as to invite him/her to verify or elaborate on the observation made, without however interpreting, but discussing only that which was seen.

Non observance by the coordinator of these aspects could lead to running the risk of not taking advantage of the benefits present in the innumerable musical aspects, such as the esthetic and sonorous experiences and the universe of expressive communication resources and artistic production, so that only an instrumental communications prevails, congruous with the preventivist model.

As regards rescue of childhood memories in the group, by means of popular songs, some authors ${ }^{(16)}$ have explained that this rescue is due to the fact that at this stage of life, the child is conveyed to the melody of the "lullaby" it heard since the time it was in its mother's lap, a song that unfolds in other melodies throughout his/her life, all in an evolutionary continuum of children's communication and socialization. In this sense, lullabies, the songs sung in circles, repertoires of social parties and religious celebrations have shown a sonorous history that helps in the articulations made during the process of man's socialization(17).

These facts lead to man's capacity as a symbolic being who, when reflecting human action, consists of forms of producing feelings. These are forms which, at the same time in which they initiate feelings, lead to other meanings that open man's symbolic imagination, understood as the human capacity to create meanings ${ }^{(18)}$.

From the point of view of communication, it is therefore, relevant for the coordinator to know how to understand this symbolic dimension as one of its constituent elements, as this means thinking that communicative products have this dimension of initiating meaning, which is found in man, but when this is inscribed in products, it gains a dimension of its own ${ }^{(19)}$.

About the use of music to perform relaxation, it is pointed out that when music is used as equilibrium and harmony, it acts as a qualifier of space, stimulating environmental and bodily perception. In addition to this, it creates a welcoming atmosphere, significantly contributing to the production of health in these spaces dedicated to care.

Some authors ${ }^{(16)}$ have ratified the need for having a more cheerful environment favorable to learning by means of music; after all, to favor joy that will be experienced in the present is a fundamental dimension of any educational activity, and it is necessary for the efforts of participants to be stimulated, compensated and rewarded by joy that can be experienced in the present moment.

Here the concept of joy according to the Snyderian concept is rescued(14), which is understood as the joy of understanding, feeling, discovering reality, being able to decipher it and act on it, to break with insecurities and uncertainties and seek it fully/ plenitude. The joy that this philosophy has in mind is to seek originality, creativity, overcoming-oneself, and constant growth of the potentialities of individuals, the suppression or diminishment of insecurities, fear and uncertainties. It is the joy of knowing, getting to know and being able to critically choose the various possibilities offered by reality.

With regard to the late arrival of a member of the group, it is pointed out that it is the knowledge that this arrival is an aspect that almost always causes the coordinator a great deal of anguish(20). In this study, it was however, observed that it is possible to deal with this in a good way. Some coordinators, when recognizing the presence of the other person, communicate the person's arrival to the group in a differentiated manner, without reprehension, without criticism. Moreover, with music, welcomes the person in a proactive and receptive way, and accompanied by the other members, which favors the integration of the latecomer participant.

It is pointed out that melody and rhythm are elements that form part of collective life, and therefore collaborate in the person's integration into the group, as they are rooted in the action, which is simultaneously corporal and socialized ${ }^{(16)}$.

About the senior dance one remembers that it was created as a preventive strategy against inactivity and to retard senility, promoting quality of life among the elderly(21). Their pieces of music are joyful and animated, with melodies that remind one of songs that one danced to in a circle in childhood, thereby rescuing musical memory. The choreographies stimulate the elderly in a playful manner in interpersonal relationships, promoting a feeling of welcome and affection. It is a circle of inclusions in which everyone appreciates himself/herself as a human being. In addition, the choreographies stimulate recent memory, attention and concentration, and may avoid isolation and provide socialization, finding new friendships, joy, motivation, entertainment and well-being ${ }^{(21)}$.

From the Snyderian point of view, one could say that the movement provided to the group by senior dancing acquires a bodily existence: "[the music] puts 
the body into motion, makes it vibrate in a manner not comparable with other forms of art; and it is the fact of being inscribed in our bodies that provides so much acuity to musical emotions"(16).

With regard to the activity of singing in a group, it seems that the coordinator intends working from the perspective of an organization that is concerned with guaranteeing the satisfaction of involvement, because without pleasure, no one becomes effectively involved. It is complicated working with someone who feels obliged to appear (at meetings) and feels no pleasure in being present. Certainly there are many themes that need to be discussed in groups, however, it is better to work from the perspective of satisfaction and coresponsibility for the elaboration of a project, than with the idea that the entire group is obliged to participate in the educational activity proposed(14).

Moreover, there is joy in the act of singing together, as it induces the group to pursue a musical objective and the project of constituting, vivifying themselves as a solidary group. The members were shown to be jubilant with the collective power and emotion, whose structure and rules are gradually created and thus establish their validity. Thus, there is a diversity that tends towards unity, in which each party finds support in the others and strengthens itself with the others in a unity that also extrapolates the walls of the health services, and expands towards to community, leading to joy by means of the "Serenade of the Bedridden"(16).

Furthermore, in this study, a tendency could be seen in the groups of breaking with the traditional model of communication, in the direction towards spaces to encourage critical thinking, thus cause an improved practical conduct of the participants and coordinators in the face of reality. When imprinting another dynamic on communication, distinct from that described by the informational model centered on disease, this study provided indications that allow one to say that the group coordinator begins to no longer see communication as the transmission of ready-made contents, but as a process of production of social meanings(10), in agreement with the presuppositions of the New Promotion Model ${ }^{(9)}$. The group therefore, appears as the space for incentive to critical thinking, which demands a discussion of one's own knowledge as an element of a reflexive proposal on reality.

However, this new trend needs to allow the development of critical sense, not only when the coordinator problematizes the reality of the participants in the group, but when the coordinator offers the historical content that each activity imposes, and other tools that help with the group's philosophical posture ${ }^{(22)}$.

Thus, it is known that in the attempt to displace communication from the limits of its instrumental doing to the space of reflection, the coordinator's action is frequently intuitive, presenting little understanding of the theoretical concepts on which the practice of groups and communication is founded. Consequently, one could expose the other members to damaging consequences, with the triggering of group phenomena such as aversions, unnecessary conflicts, suffering and loss of interest and motivation for care.

Respect for the musical style must form part of the group's sonorous universe, and of the knowledge that listening to music integrates historical, social and cultural elements of people in an intentional and organized manner, so that it is important to consider the individuality of each person. However, people do not always feel touched by the same songs, and nor do these songs play at the same time. Resulting from this is the need to focus on styles and listen to works of different natures, in order to hope that among these, each member of the group will find something that pleases him/her - and that from this, perhaps others will be reached(16).

Thus, it is important to consider the cultural universe of the group, open spaces so that it can expose itself without shame and censure, without fearing that its particularities will allow it to be underestimated; bur rather, where its experiences contribute to the growth of the group and make it more interesting and potentiate the musical moment.

When studies have shown that the main referential adopted for conducting groups is still that in which the individuals participate in meeting to acquire knowledge and change their manner of living into that which, for the team, is not healthy or may cause damage ${ }^{(23)}$, it is clear that by means of music it is possible to innovate the educational activity in groups, in agreement with the conservative practices that are still prevalent.

Moreover, it is necessary to give visibility to the groups that practice music, showing them as models that strengthen other forms of communication among the members and the community.

\section{Conclusion}

This study allowed one to find that music may be used in its affective, recreative and reflexive dimension in educational group in Family Health, making it possible, for example to bring out nuances of the past life of each 
member of the group, perform relaxation by means of verbal induction and insert differentiated activities into the group, such as the senior dance and the Serenade to the Bedridden, or even enable the exploration and problematization of situations experienced in the group, mediated by music.

These activities promote a welcoming, joyful and pleasurable space, from the daring, creativity and desire of the coordinator to change the education practice, making it possible to overcome pathological barriers that are still very present in the educational groups.

However, it was observed that the coordinator has difficulties in accurately perceiving the messages that emerge from the group, particularly those that denote the emotive effect among the members.

Therefore, it is worth emphasizing the importance of the development of coordinator training programs, by means of workshops that allow knowledge to be acquired in the areas of music and education and the constant follow-up of practices developed by these agents in their musical activities, enabling improvement of the actions already exercised and the realization of new products.

Furthermore, it is believed that it is of immeasurable importance to incorporate courses that focus on music in the group context into Undergraduate Courses in the health area. One may also not forget the importance of disseminating Specialization and Post-Graduate courses on the use of music in the area of health, which allow pertinent researches to be disseminated to Nursing and in the area of health, considering the need for changes in the practices in the service, with one of these being health education in the constitution of subjects who are co-responsible for the health system.

It is emphasized that this subject has not been frequently approach and does not form part of the lists and reflections in technical, undergraduate and Post Graduate courses. Thus, one observes that suggestions such as these are essential, in order to have coordinators in the future, which are capable of developing their potentialities as facilitators of a process that occurs in a joint and shared manner, with their peers, in the sense of exchanging learning. Fragmented concept between theory and practice still dominate the academic environments, in addition to an instrumental vision, based on reason and detached from feeling, perception and action.

\section{References}

1. Leão ER. Dor oncológica: a música como terapia complementar na assistência de enfermagem. Bol Epidemiol Centro Estud Pesqui. [periódico na Internet].
2002. [acesso 11 ago 2006]. Disponível em: http://www. hospitalsamaritano.com.br/boletimcentroestudos/1/ doroncologica.htm

2. Dobbro ERL, Silva MJP. Música na fibromialgia: a percepção da audição musical erudita. Nursing. 1999;19:14-21.

3. Lee YY, Chan MF, Mok E. Effectiveness of music intervention on the quality of life of older people. $J$ Adv Nurs. 2010;66(12):2677-87.

4. Andrade RLP, Pedrão LJ. Algumas considerações sobre a utilização de modalidades terapêuticas não tradicionais pelo enfermeiro na assistência de enfermagem psiquiátrica. Rev. Latino-Am. Enfermagem. 2005;13(5):737-42.

5. Correia MA. A função didático-pedagógica da linguagem musical: uma possibilidade na educação. Educar. 2010;36:127-45.

6. Dicionário Interativo da Educação Brasileira EducaBrasil [periódico na Internet]. São Paulo: Midiamix Editora; 2002. Pedagogia progressista; [acesso 10 nov 2011]; [cerca 1 tela].

Disponível em: http://www.educabrasil.com.br/eb/dic/ dicionario. asp?id=153

7. Snyders G. Entrevista com Georges Snyders. 1990; p.159-64. [acesso 10 out 2011]. Disponível em: http:// www.crmariocovas.sp.gov.br/pdf/ideias_11_p159164_c.pdf

8. Fernandes MTO, Silva LB, Soares SM. Utilização de tecnologias no trabalho com grupos de diabéticos e hipertensos na Saúde da Família. Cienc Saude Coletiva. 2011;16:1331-40.

9. Santos LM, Oliveira EM, Crepaldi MA, Da Ros MA. Actions of health group coordinators within the teaching/ care network. Rev Saude Pública. 2010;44(1):177-84. Inglês, Português.

10. Araújo IS de. Mercado Simbólico: um modelo de comunicação para políticas públicas. Interface Comunic, Saude, Educ. 2004;8(14):165-78.

11. Andaló CSA. O papel de coordenador de grupos. Psicologia USP. 2001;12(1):135-52.

12. Fontanella BJB, Luchesi BM, Saidel MGB, Ricas J, Turato ER, Melo DG. Amostragem em pesquisas qualitativas: proposta de procedimentos para constatar saturação teórica. Cad Saude Pública. 2011;27(2):389-94.

13. Campos CJG. Método de análise de conteúdo: ferramenta para a análise de dados qualitativos no campo da saúde. Rev Bras Enferm. 2004;57(5):611-4.

14. Snyders G. A alegria na escola. São Paulo: Manole; 1988. 284 p. 
15. Salgado GB. Grupos sociais e instituições: comunicação, interação e recepção. Psicol Pesqui. 2009;3(1):3-15.

16. Snyders G. A escola pode ensinar as alegrias da música? 2. ed. São Paulo: Cortez; 1994. 175 p.

17. Scherer CA. A contribuição da música folclórica no desenvolvimento da criança. Educativa. 2010;13(2):247-60.

18. Araújo AF, Teixeira MCS. Gilbert Durand e a pedagogia do imaginário. Let Hoje. 2009;44(4):7-13.

19. Simões PG. Para uma abordagem das interações comunicativas. Verso e Reverso/Rev Comunic. [periódico na Internet]. 2007. [acesso 25 abr 2012];21(46). Disponível em: http://www.revistas.univerciencia.org/ index.php/versoereverso/article/view/5776/5234

20. Mota KAMB, Munari DB. Um olhar para a dinâmica do coordenador de grupos. Rev Eletr Enferm. 2006;8(1):150-61.

21. Oliveira LC, Pivoto EA, Vianna PCP. Análise dos resultados de qualidade de vida em idosos praticantes de dança sênior através do SF-36. Acta Fisiatrica. 2009;16(3):101-4.

22. Snyders G. Pedagogia progressista. Lisboa: Livraria Almedina; 1974. 226 p.

23. Fortuna CM, Matumoto S, Pereira MJB, Mishima SM, Kawata LS, Camargo-Borges $C$. Nurses and the collective care practices within the family health strategy: salud de la familia. Rev. Latino-Am. Enfermagem. 2011;19(3):581-8. 